\title{
Spellbound: Typography and the Concept of Old-Spelling Editions*
}

\author{
RANDALL McLEOD
}

This paper consists of extracts from an extended account of Renaissance typesetting problems. It differentiates old spelling from old typesetting, and asserts that editorial uses of the former concept lack philosophical rigour, and that its general application in so-called old-spelling editions has distorted the subtle texture of accidentals which they are designed to convey.

The prime facie evidence is limited to ink on paper, from which can be inferred an arrangement of typefaces and types during printing. The relationship of printed image to typeface and to type is concrete, and our inferences about composition are necessarily tied to an actual historic event. Inferences about spelling, however, are highly abstract, and we have no clear evidence a given compositor spelled as he set type. There is something about spelling, this editorial abstraction, both in theory and certainly in practice, that smacks of "spurning the base degrees." Once we have made the abstraction, we pull the ladder up after us, and, though we may lower it in a new old-spelling edition, we have grossly altered material circumstances. We are headed for a fall to the extent we take pride in our conservatism.

Let us look first at the early quartos of Dekker's Shomakers Holiday. In signature $\mathrm{B}^{\mathrm{r}}$ of $\mathrm{Q} 3$ we find

\section{arsong ft.}

The $\int$ and $t$ constitute one graphic shape, a ligature, printed by one type, noteworthy in that it back-kerns. A kern is vulnerable typeface that extends off its own typebody. To survive printing it must be set where it can rest on an adjacent type shoulder; but as the $g$ occupies

*An earlier version of this paper was presented at a conference on "The Preparation of OldSpelling Renaissance Play-Texts in English," Glendon College, York University, April 12-13, 1978. 
this very place, $f t$ cannot be set after $g$ without causing the kern to foul, and thus to bend or break:

\section{amongft}

Accordingly, we can deduce the gap between the $g$ and the $f t$ correlates in the original setting with spacing type or types. Now look at the equivalent passage in Q1 and 2.

$$
\text { amongef }
$$

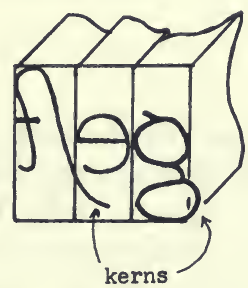

Is $e$ part of the spelling? part of the pronunciation? Is it not perfectly plausible that the $e$ is merely a weak vowel whose body is being used by the typesetter, who may care nothing for her intelligence?

About "amongest." We can look to the $O E D$ spelling profile (arranged grossly by centuries), and find that "amongest" is a legitimate 16thcentury "spelling," but not 17 th. But how does the $O E D$ know what the spelling is if it gathered its information from type, since the whole question of the spelling per se of this word in type (though not, perhaps, in ms.) is challenged by the example from Dekker? Unfortunately we frequently cannot separate ms. "spellings" from type "spellings" because the sources of the profiles are not extant. As there is no Dekker concordance, the prevalence of the form in his work cannot easily be determined. But what would any other italic occurrences tell us, for there is no ready way to surmise a ms. value through such type exigencies? It would be interesting to learn if the e were found only in italic settings, where alone the fouling potential exists. (Q1 also offers two settings each of "amongst" and "among" in black letter.) More than a Dekker concordance we need one for Valentine Sims, the printer, and an analysis of his founts and compositors. Some founts, by the way, had a nonkerning allotype of the ligature, and contemporary examples of this rarer type are not hard to find, though there is none in Shomakers Q1:

\section{Amongst.}


A spacing e is to be suspected elsewhere and in non-italic settings: roman "stiffely" (Hamlet F1); and in black letter, disyllabic "muffeled" (Shomakers Q1); "trifell" and "trifle" are both found in Lear Q1; "croffely" (Richard II F1), "grofely" Shake-speares Sonnets Q1), both disyllables. Is the form "de fleigne" (Hamlet F1, 2) an etymological spelling? a phonetic spelling? a type-exigent setting? all three? And are we to discern a spacing $\mathrm{u}$ in "baffuld" in Richard II Q1, where F1 prints "baffel'd," and Rowe prints "baffled"?

How frequently do such typesetting problems undermine the validity of the spelling concept? Here follows a sketch of sample typesetting problems in typical italic faces of the day-italic had (and has) more kerned sorts than black letter or roman founts. The problematic words are given arbitrarily in a modern face, but the reader can reconstruct the Renaissance potential for fouling with reference to this hand-drawn classification of italic shapes in which the vertical stroke isolates the kern:

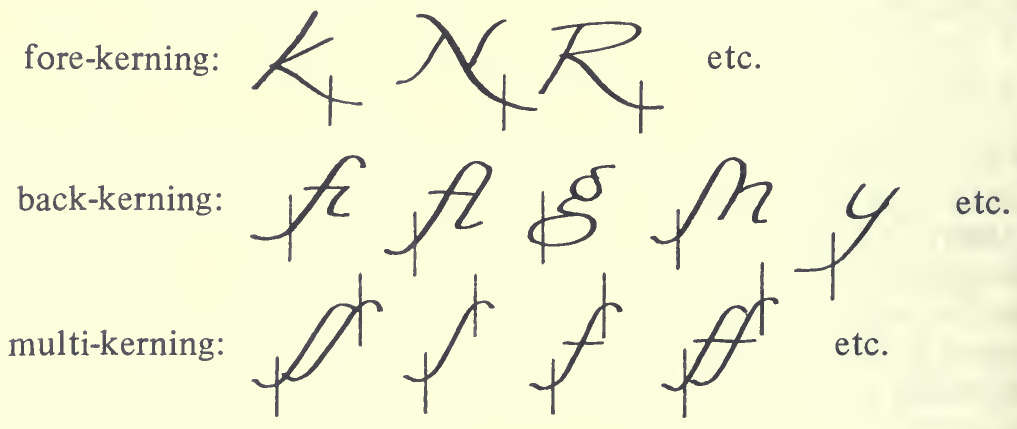

Here are several random examples: pickpocket $(k+p)$; pricksong $(k+s)$; kiss'd (ss+'); Yorkshire $(k+s h)$; thinkst, and all such verbs ending in $-\mathrm{k}$ $(k+s t)$; breakfast $(k+f)$; stockfish $(k+f i)$; thick-flowing $(k+f l) ; k y t h(k+y)$ offshoot $(f f+s h)$; offhand $(f f+h)$; doffst $(f f+s t)$; kingship $(g+s h)$; bringst and all such verbs ending in $-g(g+s t)$; eggshell $(g+g+s h) ; s k y(s+k+y)$; selfhood $(f+h)$; Nym $(N+y)$; Ryme $(R+y)$; Rose $(R+s)$; dissēble $(s s+\bar{e})$ with this example one senses the profound typesetting problems in accented languages with kerning sorts; and finally a word that for many modern readers must define the oddity of this design characteristic of old italic - assbackwards $(s s+b)$. For many of these incompatibilities graceful solutions existed somewhere before during or after our period - solutions that did not upset the equation of spelling and typesetting; but not all the solutions are to be found in any of the old founts. 
The settings of some words inevitably involve a string of incompatible types: $s k y$, for example would foul like this:

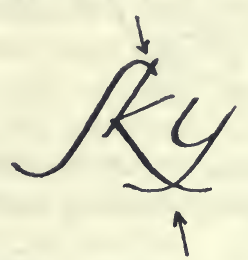

-with the result that it is likely to be set:

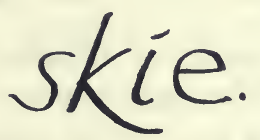

The word "kiss' $d$ " fouls like this:

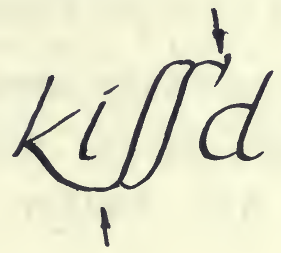

-and thus calls for these settings:

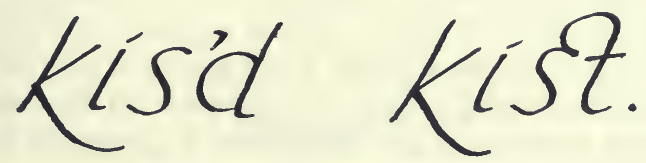

If the $\mathrm{k}$ of the fount lacks a kern, then:
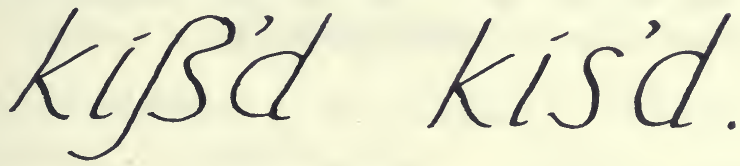

Or if the apostrophe is low slung as well, then - at last -
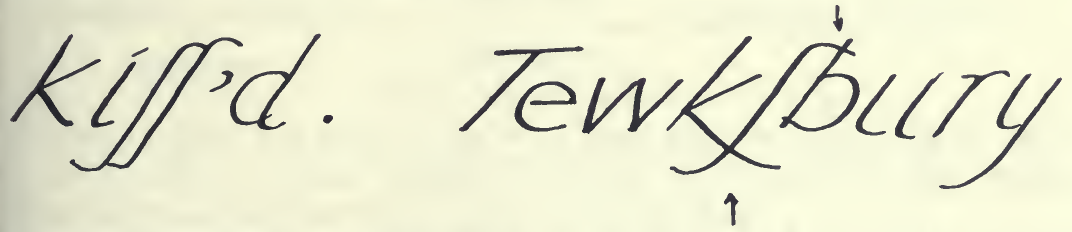

can be resolved easily with a round $s$. 


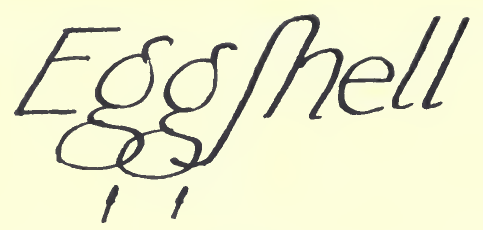

needs to space one $g$ from the other or eliminate one of them, as the $g g$ ligature and $g$ allotypes which existed in early Italian printing

\section{Saggio}

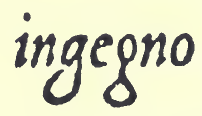

seem not to have been current in Elizabethan and Jacobean founts. Furthermore, there is need to space the $g$ and $\delta$ with a dash, an $e$, or both (though a round $s$ and an $h$ would neatly solve the problem tooand this is the obvious solution for continental founts, used in the dedicatory notes to Shakespeare's Venus and Lucrece, that are short of $\beta$ ligatures).

Here are some examples of problematic settings and resolutions:

publikely publickly tbankful Quickely 2rickly fruckst difrëb: Reprouers ofpriclatic oppoiles Rete Maskers Mrafque Mafke.

What is the name of Troilus' love? The Quarto offers us three options, Cressid(a), Cresseid(a) and Cressed, the variation in the number of syllables being perhaps a metrical accommodation (although the variation is found in prose). Scrutinizing the actual typesettings in the stints assigned by Williams and Walker ${ }^{1}$ we can see that each compositor sets type in peculiar ways not accounted for by the concept of spelling.

Typeface

Frequency

$\begin{array}{crc}\int i & \text { Comp. A } & \text { Comp. B } \\ \int+e+i-17 & 1 \\ \int+\int i+e & 13 \\ \int+e-2 & 0 \\ \int+s+e+i r \frac{-0}{32} & \frac{1}{15}\end{array}$


The matter is more complicated, obviously, than can be revealed by saying, as does Walker, that Compositor A is a Cressida speller and B a Cresseida speller. ${ }^{2}$ B's settings show consistent sensitivity to the kerns of his types, and the $e$ in the name can be explained in each instance (except in the one $\int s e i$ setting) as a spacing function. This unique setting might be taken as a spelling preference since the $e$ is typographically not required, but as it comes late in the quarto we might suppose that the compositor's typographical practice has led him to think of $e$ as inevitable in the name. Oddly he uses the $\iint_{i}$ ligature once $\left(I^{\mathrm{V}}\right)$, and this fact calls for explanation by analysis of the cases or perhaps for reassignment of compositors or their cases. Compositor A's disregard for kerns is borne out by other examples, as on $\mathrm{K} 4{ }^{\mathrm{V}}$ where we find

\section{Crefid, Crefid, Crefjisi, and V'Vereita Calke compord by Vulcans skill}

the latter part of which shows a fouling of $\uparrow$ on $\mathrm{k}$ and ' and the usual avoidance of fouling on $\mathrm{k}$ by use of the round $\mathrm{s}$ before it. This typesetting behaviour, if consistently A's, should serve to assign the stints in Shake-speares Sonnets (by the same printer in the same year) differently than they are now assigned. ${ }^{3}$ Such speculation is closed on these matters, however, if we think only in terms of spelling and not of typesetting.

$* * *$

The name "Quicksilver" in Chapman, Jonson and Marston's Eastward Hoe Q1 presents no problem to the typist, or to the compositor setting roman-

\section{Quickifluer,}

or italic, if the $k$ is mis-set as $h$ :

\section{Quichgluer.}

But when the kerned $k$ is set we get this mess-

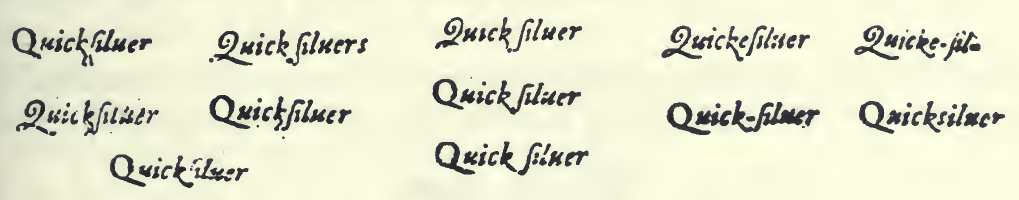

-in which either the dash or the $e$ or both may be type-exigent. How are we to see ms. values through this haze? How are we to say where words begin and end, or what is true compounding?

These equivocations mean that typesetting problems within a word spill out beyond that word. We are now unable always to determine 
where some words begin and end, though with an eye on the original type sorts and their settings (something we cannot see in our old-spelling editions) we can divine within loose limits the compositorial options and exigencies.

There are $\mathrm{u} / \mathrm{v}$ allotypes, just as there are $\mathrm{f} / \mathrm{s}$ allotypes, and they both can function to differentiate the ends of words from the middle. Their levelling in some modern old-spelling editions obscures the kind of information we see in the originals themselves; consider these examples from Shakespeare's Sonnets, 1609:

\section{rousd vnovid vnvids.}

This last might be a typo, though the orderly progression of examples suggests otherwise. There is a possibility that such settings imply something of an etymological attitude in the ms., as we find a $\mathrm{v}$ in Daniel's abbreviation of "perused," "pvsd," though he also uses u medially elsewhere in the same ms. ${ }^{4}$ The subtlety is found again (to return to $\mathrm{f} / \mathrm{s}$ ) in these examples from Eastward Hoe:

\section{Tradefmen tradesmen Trades-man Tradef-man.}

The example with $f$ and -, where there is no potential for fouling, suggests that the word is a unit of two halves, whereas the s and - suggests compound words. This problem is frequently encountered in Latin around the question of separable and non-separable affixes:

\section{nobiscum pignoribufq.}

Such subtle distinctions are confounded in editions that "normalize" $f$ and $s$.

Finally there are other important ways in which the typesetting of one word may influence that of another. Consider this example:

\section{Worke epex.}

As the kern of a terminal $k$ tends to carry across the interlexical space and to beg the eye to see different words as one, the $e$ functions graphically to consolidate the word shapes. It is obviously not needed here, however: 


\section{vuctoaksQusc.}

Neither the $e$ nor the $s$ avoids fouling, though the $e$ does have a spacing function. In these next phrases, however, the spacing $e$ is required to avoid fouling unless the compositor opts for an awkward pigeon hole:

\section{alacke for the mulikeplaies.}

Consideration of the setting of a word with relation to the surrounding type and line length may lead beyond the question of spelling to that of diction - as, for example, in the case of irregular use of "has" and "hath" in Shakespeare's texts. Consider, for example, these lines from Troilus and Cressida (F1):

\section{Cre. Why Paris hach colour inough. Pan. Solbehas.}

Now, we are accustomed to contemporary "spellings" that fluctuate even in the same line. But the change from "hath" to "has" in adjacent speeches may strike us as odd. The question cannot be adequately assessed with reference only to this setting. Let us look at its copy text, Q1 (1609), where we find not two lines, but one line, and justified at that:

\section{Cref. Why Pa is harh colour inou;h. P.znd.So he has.}

The supposition is unavoidable (if unprovable) that had the compositor's stick been several $\mathrm{mm}$. longer, we would find "hath" twice in this line. Is this a question of compositorial "spelling" or compositorial diction or is this a variation from the author? In Troilus Q1 we find 16 uses of "has," (11 "justified") against 62 uses of "hath" (only 8 "justified"). Now, the "justification" of lines often has to do with their being in prose, and prose has a tonality different from verse and hence a different diction. So it may be that the forms vary by verse and prose; further analysis is required to separate such potential causes.

There are twelve speakers in Troilus that use "hath" only and four that use both "hath" and "has." None uses "has" exclusively. These varying uses can be organized according to appearance in the so-called justified or non-justified lines, and in prose or verse, and I shall summarize the salient points of this comparison. ${ }^{5}$

1) Pandarus' five "has" forms all occur in justified prose lines. One use, photo-quoted above, accompanies "hath" by Cressida at the start of the same prose line, all of which suggests that "has" may be typeexigent. Pandarus' single "hath" occurs in unjustified verse. There is no clear reason, then, to think that "hath" is for verse and "has" is for prose. 
2) Cressida's single "has" form occurs in a justified prose line that comprises her whole speech, there thus being no chance to run over. Her three "hath" forms occur once in justified prose, once in unjustified verse, and once in an unjustified pentameter line in a prose context. The conclusion is the same; we cannot discriminate the uses of the forms in terms of verse and prose, but we can do quite well on the basis of spacing.

3) Thersites uses "ha's" twice and "has" five times. His speeches are in prose, and thus almost all occurrences are in justified lines. His single "hath" form occurs in a justified prose line, which ends "hath no"/, and if instead of these seven types were set these six, "has no"/, a pigeon hole would develop. As I formerly suggested that "has" might be a space-exigent form of "hath," here we can surmise that "hath" may be a space-exigent form of "has."

4) Finally, the evidence of Ulysses: in the main "hath" (fourteen times) though occasional use of "has" (three times, once in prose, TLN 1300 , and twice in verse, 1979,2663 ). Let me analyze just the first occurrence of "has." "Has" occurs in 2.3 , just at the end of the first (prose) half of the scene. Before the "has" is a "hath" by Ulysses in an unjustified prose line (1295); and after it comes his "hath" in an unjustified verse line (1309). The justified "has" line in question, 1300, occurs in the midst of a heavily cramped section of E1V , in which the line before and the second and third lines after are all justified and contain tilde contractions. Once again variation seems well explained by type spacing. ${ }^{6}$

I have not attempted a systematic analysis of all uses of "has" and "hath" in the play. Such analysis would inevitably involve discussion of the endings "-s" and "-eth" in the third person singular indicative of most other verbs, and this is beyond the point raised here, which is simply to raise the question of whether material causality can dominate formal causality in this case. If it can, then it may be that neither form prejudices the pronunciation (or pronunciations) of the word, except in rhyme position. Linguistic information from Renaissance times suggests that the written form "hath" was becoming or was already a literary form. But was it a visual literary form, or a form of literary diction which idea of diction implies pronunciation? The general situation for the typical third person singular indicative endings of verbs was not in doubt to Richard Hodges in 1643, when he said that "whensoever eth cometh in the end of any word, wee may pronounce it sometimes as $s$, and sometimes like $z$." This statement must apply to the very "cometh" in his own sentence, which we should thus sound with a $z$. (Caught you, didn't he!) In the face of this statement the practice in modernizing editions of Shakespeare may be questioned for potential inconsistency 
- for printing "cometh" when the copy text reads "cometh," "comes" when it reads "comes," when rhyme or metre do not specify the "-eth" pronunciation. We have to learn whether the practice of 1643 pertained a half century earlier. Typographical analysis may well prove crucial in answering this question, certainly in stating its limits. Again, the most efficient description of the text is typographical. Spelling begs a host of questions.

It is time now to spell out some of the implications of this evidence. I shall refer to only a handful of examples, but the problems illustrated are typical of the handling of textual subtleties throughout the field. The Shakespeare Variorum Handbook opts to keep old u, v, i, and vv since they may hint at the copy text. "Although the same argument could be made for retaining the long-s for modern s, it seems doubtful that the great trouble and expense necessary to retain it would be justified by the few occasions when long-s and $f$ are confused, since such a case of ambiguity as fight/sight may be easily explained in the commentary notes. Long-s will therefore be normalized to modern s." 8 Similarly Fredson Bowers argues for an "old-spelling text, not a modernized version that constantly draws a veil between him [the reader] and the subtleties of the original," but the "pedantic use of long s," etc. is rejected." M.J. Pearce, who models his Workbook of Analytical and Descriptive Bibliography on Bowers' work, states that although the long $\uparrow$ should be transcribed "as found," ligatures in $\int$ "must" be ignored and the constituents spelled out. ${ }^{10}$ Behind the words like "normalize," "pedantic," and the imperative "must" lies a failure to comprehend the typographical issues. The strongest reason for abandoning the allotypes of $\mathrm{s}$, a feature of our written and typeset language we share in common with German, ancient Greek and Hebrew, in which printing traditions they are still in active use, is economic: the Variorum Handbook says the differentiation of these allotypes costs too much. But economic costs are to be calculated against the intellectual costs of directing our discipline away from primary material and primary material. Professor Bowers suggests hopefully that in old-spelling editions a note might be given for specialists (which means, I imagine, that it will be ignored), so that they can restore "automatically" the typographical form of the original." But as we have seen, no typesetting is likely to sort with any automatic rule.

In its note to prospective editors on typographical format, the Variorum Handbook does not address the problem of ligatures (which one encounters in every line of old editions, but much less frequently in the modern Variorum editions), though it does tell how to handle certain 
logotypes, which it strangely calls "digraphs" (which term I cannot find in any dictionary of printing, though it is a term in linguistics). Even when the Variorum did employ old ligatures, it could misapply them. Here from Venus and Adonis 832 are the Variorum and the Q1 version:

\section{Paffion Palfion.}

This practice tends in the direction opposite to that of the modern oldspelling editions, but it is still "normalizing." One suspects that in new Variorum editions the w at the start of this line is to be "normalized":

\section{which with cold terror, doth mens minds confound: .}

But as the line is justified, and as there is no room for the regular VV, it is surely intentional, and likely a compositorial correction of a VV setting in order to justify a line that proved too long as he was setting it. Rollins' conservative edition of Venus, by the way, kept the line as is. In the textual notes to 106.7 in Rollins' edition of Shakespeare's Sonnets we find that "exprest" in Q1 becomes "express" in the early 18 th century. There is no way to tell whether the ss of "express" refers to an ff ligature (hence perhaps an easy ty pesetting error), or fs (hence likely an intended change). Cutting corners on typesetting costs in such scholarly collations greatly increases their ambiguity, and decreases their scholarly value.

The Handbook suggests that the $f$ in "sight" gets confused with the $f$ in "fight." That is true enough (really it means fi and fi ), but there are more, and more important confusions that are passed over. A late quarto of Hamlet is reported to read "puer as Snosh," which misprints "pure as fnow" in Q2. Behind the "Snosh" must lie "Snofh," but if the ligature is abandoned the error becomes unintelligible. If it is retained, the reader can see that one type has been substituted for another type, one that lies adjacent in the old case, and which has a similar set. Typically, Midsummer Night's Dream collations give "take Q] taste F." The speech in 5.1 is full of malapropisms and makes Bottomless sense either way. The nature of the problem comes into sharp focus when we realize that $\mathrm{k}$ and $\mathrm{ft}$ lie adjacent in the early case and have similar sets. No such explanation can apply, however, to the variant between editions of Richard II "taske] take" (which looks like the former collation in modern type), as the $\mathrm{k}$ ligature was not in use until over a century later. Does the form "prasi'd" in collations of Troilus refer to an fi ligature or to $\boldsymbol{C}$ or to s? Once we know it is 
matched by

$$
\text { Prais's }
$$

a few lines later we have the answer: a round $s$ has been used to avoid fouling on an apostrophe, and it has mistakenly been interchanged with i. Had the ligature been found we would have a significant crux. How is the reader to know from the collation?

In Delia Q1 look what we lose by levelling the allotypes of s. Signature $\mathrm{C}$ shows the following distribution of sh and $\mathrm{h}$ ligature. Signature B is all sh, signature D and following is (with an odd late exception) all Th ligatures.

$\begin{array}{lcccccccc} & 1 \mathrm{r} & 1 \mathrm{v} & 2 \mathrm{r} & 2 \mathrm{v} & 3 \mathrm{r} & 3 \mathrm{v} & 4 \mathrm{r} & 4 \mathrm{v} \\ \text { outer C } & \mathrm{sh} & & & \text { sh } & \text { sh } & & & \mathrm{fh} \\ \text { inner C } & & \mathrm{fh} & & & & \mathrm{fh} & \mathrm{fh} & \end{array}$

Here is evidence that $\mathrm{C}$ was likely set by formes, not seriatim; that copy was cast off, the outer forme set first; and that the fourth page was set last in the forme. Had this evidence been known several decades ago it would have challenged more than one of the prevalent misconceptions of the day. This pot of gold has nothing to do with the confusion of $f$ and $\mathrm{f}$, which issue is a red herring drawn across the entrance to the rainbow. The sequence of composition of pages and formes may not contribute directly to the meaning of the poem, but it tells us something about the likelihood that Daniel's ms tendency to avoid long $\Upsilon$ is not an influence on the compositor(s) here, though it may be in random occurrences later in Q1 like

\section{falsed or confused}

Even Charlton Hinman in his Printing and Proof-Reading spoke of signature $f f$ in the Folio, whereas the ligature is not generally used for signing in printing, and is certainly not used in the Folio. This is a minor case perhaps, but what are we to do with his list of variants, ${ }^{12}$ when his

\section{fir] \\ fir],}

Norton Folio shows the second reading at least to be incorrect, as the fi ligature is used? If we cannot find consistency in this conservative study, can we trust this report in the Cambridge Dekker from a list of press variants in which list the highest typographical fidelity is to prevail: ${ }^{13}$ 


\section{Gip $[i e]$ gipfre fings] flings.}

Othello collations give "meslt," which begs the question of the ligature and allotypes in the original, but $\mathrm{Q}$ reads merely "mes lt." In a modern old-spelling text we are likely to meet "i'st." Does this record an original error in the placing of the apostrophe? Not likely, if ft was used: contrast

\section{is't with I'At.}

Similarly the form "dan'st" (i.e. "danced") looks odd in modern type, but the reason for it is obvious when we remember the ligature.

And consider this textual note: ${ }^{14}$

\section{ceaslesse] $S, P$; cealesse $Q$.}

Perhaps the editor has made the obvious lexical correction. But if we had to defend the obvious, as each self-scrutinizing discipline ought, the rationale becomes very complicated. The insertion of an s in the modern text hides the question of why $\mathrm{ll}$ was not used in the original (can we detect a type shortage here?), and the corollary question of which allo-

Neither can it be of differvice to Authors who correkt their own works, and who ought to be atquainted with Ligatures, and conpound Sorts, to mark them according to their contents : for it has been obferved, that even young Cortectors have marked only one part of a ligature; as, the $f$ of $\mathrm{f}$, ta be alter'd into an $\int$; the $k$ of $n k$, to be turned into $a b$; and fo in other cafes, fimilar to thefe; whereas they would have marked the whole ligature $f i, f$, arc. had they iaken notice, that thefe and fevcral other Sorts are caft in a piece, for the reafons which have been given before.

Smith, Printer's Grammar, 1755, p. 82

type of $\mathrm{s}$ was used (omitted, rather). So the $\mathrm{Q}$ setting is strange indeed; it may imply a ligature shortage made good by setting type by type, and then made bad by loss of one of the types. And who is to say that the missing type is not "whorson Zedd," the "vnnecessarie letter" but not the unnecessary type - because it does not kern like an $\int$ ? (Consider this collation from Troilus: 


\section{resides] $F 2$; reides $Q$; recides $F I$}

One must guess F2 uses a ligature, but on the basis of the F1 reading, as well as by typographical sense, we can see that the letter missing in Q is not necessarily an s and is almost certainly not an $\int$.) Is not "ceaclesse" a better emendation? Might it not be best to make no emendation, but to express our quandary in a note?

The last matter of the editor's art to treat is one of the most closely reasoned of all its practices. Let me quote from Greg's discussion of his Seventh Rule: ${ }^{15}$

When a correction was made in the type it often necessitated altering the form or spelling of some other word in the line in order to secure typographical adjustment. If an editor accepts the correction he should adopt the correction only and preserve the rest of the line as originally set up, this being the nearest approach possible to the form of the copy. In other words an editor should take as his copy-text the original setting of each forme, introducing into it from the corrected setting only the deliberate alterations of the press reader, or such of them as he accepts, and not the consequential changes that the compositor was forced to make.

Greg's rule deals with "accidental" changes made in other words in order to accommodate a "substantive" correction in the crux. Here is an example of this principle from the Cambridge Dekker (for Westward Hoe, 4.1.133). The press variants

\section{swaggringft wild-oats}

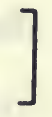

swaggring wilde-oats

lead to this in the critical edition, which reading combines (in an even less conservative type format) the new "substantive" and some of the old "accidentals":

\section{swaggringst wilde-oats.}

Now consider this alteration of type in Lear Q1. ${ }^{16}$ The words

\section{noyftles and paft}

were replaced respectively by the underlined words in these justified lines:

Wher's thy drum: Francefpreds his hamers in ournoy feles land,

fhe put rm it h pâft aliue, ine rape vm ath en:combs wir! a flicri,

The corrections, I argue, cannot be assumed to be pure, because for ease , $f$ correction they must fit into the space vacated by the errors. We have, 
then, a very good idea of the space exigencies. If $\mathrm{ftl}$ were replaced by $\mathrm{n}$, to form a common typesetting of the word, its length would fall short and create a pigeon hole, which can be rectified only by moving many types, or by hair spacing, etc. The e (with $\lceil$ and 1 ), which brings the correction to the approximate length of the fault, may, then, be a spacing e, not perhaps because there is a shortage of $\mathbb{n}$ ligatures, or a desire for etymological format, but because there is an abundance of space that must be filled in order to justify the line and to space the face. The opposite rationale applies to paft/pâft $(\mathrm{F}=\mathrm{Pafte})$ as there is no room for extra type. When Greg proposed that the other words altered in order to make space for the correction should not be so altered in his kind of critical edition, he seems to have implied that the correcting word itself might not be altered. But here the substantive correction seems likely to partake of the accidental nature of the error. How do we know what it means to "adopt the correction only"?...

\section{INCONCLUSION}

\section{Hence is it, that we make trifles of ecrours, eufconcing our felwes inco fec- ming knowledge, when we fhould fubmit our felues to an vnknowne feare.}

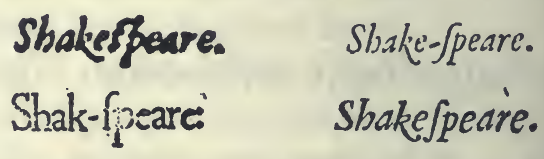

University of Toronto

Notes

1 This analysis is tabulated in T.H. Howard-Hill, ed., Troilus and Cressida, A Concordance to the Text of the First Quarto of 1609, Oxford Shakespeare Concordances (Oxford, 1972), pp. xi-xiii.

2 See her edition of Troilus (Cambridge, 1957), p. 129.

3 MacD. P. Jackson, "Punctuation and the Compositors of Shakespeare's Sonnets, 1609, The Library, 5 th ser., Vol. XXX, no. 1, March, 1975, pp. 1-24.

4 See his hand in W.W. Greg, English Literary Autographs, 1550-1650 (Oxford, 1932), section xxi.

5 I have omitted arbitrarily the compositors from the present account, as 12 of the 14 uses of "has" were set by Compositor A, as were both the "ha's" forms. 
6 Line 1300 may contain a phonetic play on "is his" and "has his."

7 E.J. Dobson, English Pronunciation: 1500-1700, 2 vols. (Oxford, 1957), Vol. I, p. 168.

8 R. Hosley, R. Knowles, R. McGugan, Shakespeare Variorum Handbook: A Manual of Editorial Practice, New York, 1971, p. 8; and supplement by J.G. McManaway, n.p., n.d.

9 F. Bowers, On Editing Shakespeare (Charlottesville, 1966), p. 164.

10 (Hamden, Conn., 1970), p. 32.

11 F. Bowers, Textual and Literary Criticism (Cambridge, 1959), p. 186.

12 Charlton Hinman, The Printing and Proof-Reading of the First Folio of Shakespeare, 2 vols. (Oxford, 1963), Vol. I, pp. 30, 295, 262, etc.

13 Vol. I, p. 493; Vol. II, p. 399.

14 The Plays of George Chapman: The Comedies, a Critical Edition, ed. Alan Holaday (Urbana, 1970), p. 54 (re The Blind Beggar 3.2.22).

15 W.W. Greg, The Editorial Problem in Shakespeare (Oxford, 1942), p. xlix.

16 W.W. Greg, The Variants in the First Quarto of King Lear (London, 1940), pp. 22-23, 30-31. 